\title{
Increased carbon dioxide availability alters phytoplankton stoichiometry and affects carbon cycling and growth of a marine planktonic herbivore
}

\author{
Katherina L. Schoo • Arne M. Malzahn • \\ Evamaria Krause $\cdot$ Maarten Boersma
}

Received: 29 December 2011/ Accepted: 1 November 2012/Published online: 21 November 2012

(C) Springer-Verlag Berlin Heidelberg 2012

\begin{abstract}
Rising levels of $\mathrm{CO}_{2}$ in the atmosphere have led to increased $\mathrm{CO}_{2}$ concentrations in the oceans. This enhanced carbon availability to the marine primary producers has the potential to change their nutrient stoichiometry, and higher carbon-to-nutrient ratios are expected. As a result, the quality of the primary producers as food for herbivores may change. Here, we present experimental work showing the effect of feeding Rhodomonas salina grown under different $p \mathrm{CO}_{2}(200,400$ and $800 \mu \mathrm{atm})$ on the copepod Acartia tonsa. The rate of development of copepodites decreased with increasing $\mathrm{CO}_{2}$ availability to the algae. The surplus carbon in the algae was excreted by the copepods, with younger stages (copepodites) excreting most of their surplus carbon through respiration and adult copepods excreting surplus carbon mostly as DOC. We consider the possible consequences of different excretory pathways for the ecosystem. A continued increase in the $\mathrm{CO}_{2}$ availability for primary production, together with changes in the nutrient loading of coastal ecosystems, may cause changes in the trophic links between primary producers and herbivores.
\end{abstract}

Communicated by S. Dupont.

K. L. Schoo ( $\square)$ · A. M. Malzahn · E. Krause · M. Boersma Alfred-Wegener-Institute for Polar and Marine Research, Biologische Anstalt Helgoland, Postbox 180,

27483 Helgoland, Germany

e-mail: Katherina.Schoo@awi.de

\section{A. M. Malzahn}

Helmholtz-Zentrum Geesthacht Centre for Materials and Coastal Research, Institute for Coastal Research, Max-Planck-Straße 1, 21502 Geesthacht, Germany

\section{Introduction}

The increasing levels of $\mathrm{CO}_{2}$ in the atmosphere have a direct effect on the world's oceans, which act as a major sink for anthropogenically increased $\mathrm{CO}_{2}$ concentrations. The resulting dramatic change in the chemical composition of the surface oceans has led to ocean acidification.

Apart from the acidification effects, the direct effects of an increasing availability of carbon in the marine environment will likely have an additional impact on marine organisms. Most likely, changes in $\mathrm{CO}_{2}$ availability will affect primary producers directly, although this appears to be highly species dependent and may not be the case for all organisms (Nielsen et al. 2010; Gervais and Riebesell 2001; Burkhardt et al. 1999; Urabe and Waki 2009; Urabe et al. 2003). The high $\mathrm{CO}_{2}$ availability to primary producers may affect their quality as food for herbivorous consumers, as the increasing carbon availability has the potential to change the balance (stoichiometry) of nutrients in primary producers thus possibly leading to limitations in other essential nutrients, such as nitrogen and phosphorus. As primary producers are not homoeostatic with respect to their nutrient composition, but reflect the nutrient composition of their surrounding medium, they are expected to show higher carbon-to-nutrient ratios when $\mathrm{CO}_{2}$ availability is high (Urabe et al. 2003; van de Waal et al. 2010). Algae with a high carbon-to-nutrient ratio are known to often be of inferior food quality for herbivorous consumers (Boersma et al. 2008; Malzahn et al. 2007; Sterner and Elser 2002; Schoo et al. 2012). At the same time, the total biomass of the producers will probably be higher as a result of the increased carbon availability. Therefore, the consumers may be faced with higher amounts of food which is of lower quality (Urabe et al. 2003). Consumers are more constrained with respect to their body nutrient composition 
than primary producers and thus have to cope with excess amounts of carbon relative to essential nutrients, due to the fact that the consumers aim to maintain homoeostasis (i.e. they maintain a constant carbon-to-nutrient ratio) (Sterner and Elser 2002). The most straightforward way of dealing with this imbalance is of course not to take up the surplus carbon in the first place or to egest it directly from the gut as faeces. This carbon would then most likely be sequestered to the deep water layers and impact the strength of the biological pump (Anderson et al. 2005). In addition, several post-absorptive regulation mechanisms exist. Surplus carbon can be excreted through different mechanisms, ranging from increased activity (Plath and Boersma 2001) and respiration (Darchambeau et al. 2003; Malzahn et al. 2010) through changes in the digestion efficiency of carbon (DeMott and Tessier 2002). Whatever the mechanisms used, keeping homoeostasis and thus getting rid of excess carbon often comes at a cost to the herbivore and hence results in decreased growth and reproduction (Boersma 2000; Malzahn et al. 2007). The pathways by which the consumers excrete the surplus carbon could have major consequences for the flow of energy and matter in the marine food web (Darchambeau et al. 2003). Carbon excreted through respiration as $\mathrm{CO}_{2}$ is essentially lost to the system, in which it is already in high supply, while carbon excreted as DOC is potentially available to heterotrophic microorganisms, such as bacteria (Saba et al. 2011). These changes in carbon availability to the marine system are likely to have other potentially far-reaching impacts on the functioning of predator-prey interactions and may therefore affect the whole of the marine food web. Changes in food quality at the base of the food web affect primary consumers and thus propagate through the food web with potentially strong negative effects on the fitness and potentially the recruitment of higher trophic levels (Boersma et al. 2009; Malzahn et al. 2010; Schoo et al. 2010, 2012). Higher availability of carbon and the subsequent changes in seawater nutrient composition, caused by the relatively lower availability of mineral nutrients compared to $\mathrm{C}$, may also cause shifts in competitive interactions between algae (e.g. Kuffner et al. 2007; Rost et al. 2003; Swanson and Fox 2007; Tortell et al. 2002), thus changing the community composition of primary producers, possibly leading to the loss of species or the replacement of some species with others. Taken together, these changes may alter the flow of energy and matter through the food web and modify the functioning of communities. In the light of the predicted increase of $p \mathrm{CO}_{2}$ and the observed trend of decreasing nitrogen and phosphorus inputs to coastal areas (Wiltshire et al. 2008), the potential for an excess of carbon and a concurrent nutrient limitation at the base of the food web is heightened considerably.
Very little is known about this 'side' effect of ocean acidification, and hence, we carried out a mechanistic study with model organisms to investigate whether the process of $\mathrm{CO}_{2}$-induced shifts in food quality could play a role at all. Thus, we investigate the effects of different $p \mathrm{CO}_{2}$ levels on the nutrient stoichiometry of a primary producer, the cryptophyte Rhodomonas salina. This primary producer, grown under different $p \mathrm{CO}_{2}$ regimes relevant to IPCC scenarios, was then fed to a key herbivorous consumer, the copepod Acartia tonsa. As a result of the different $p \mathrm{CO}_{2}$ growth conditions, a change in the carbon-to-nutrient ratios in $R$. salina is expected, which should have consequences for its quality as food for A. tonsa. In a second step, the respiration rate and DOC release of the copepods were measured to assess how the surplus carbon is released.

\section{Materials and methods}

\section{Growth rate experiment}

To assess the direct impact of phytoplankton stoichiometry on a grazer growth rate, copepods raised from eggs in control $p \mathrm{CO}_{2}$ conditions were fed with $R$. salina cultured in different $p \mathrm{CO}_{2}$ conditions. The developmental rate of the juvenile copepods was determined after 14 days.

\section{Phytoplankton}

A stock culture of the cryptophyte $R$. salina was cultivated in $f / 2$ enriched seawater following Guillard and Ryther (1962). The seawater used for the growth medium was collected prior to the experiment in one single effort, sterile filtered (sterile $0.2 \mu \mathrm{m}$ filter), enriched with the full set of nutrients for the $\mathrm{f} / 2$ growth medium as described by Guillard and Ryther (1962) and stored in a cool and dark place until required for the algae cultures. All of the algae in this experiment were incubated in subsamples of this medium.

Rhodomonas salina was grown in continuous chemostat cultures maintained at steady state. The cultures were diluted with $\mathrm{f} / 2$ medium and constantly aerated with a mixture of air and pure $\mathrm{CO}_{2}$ adjusted to one of three different $p \mathrm{CO}_{2}$. In this experiment, the $p \mathrm{CO}_{2}$ was adjusted to 200, 400 and $800 \mu \mathrm{atm}$. To achieve a pre-defined $p \mathrm{CO}_{2}$ level, the air was first stripped of all $\mathrm{CO}_{2}$ with a soda lime filter before being mixed with pure $\mathrm{CO}_{2}$. A sensor continuously monitored the $p \mathrm{CO}_{2}$ of the gas mixture distributed to the algal cultures and automatically adjusted the $\mathrm{CO}_{2}$ content and flow rate. Preliminary experiments showed that the $p \mathrm{CO}_{2}$ of the growth medium was in equilibrium with the target level of the gas $p \mathrm{CO}_{2}$ within $1 \mathrm{~h}$ of aeration. The algal chemostat cultures $(5 \mathrm{~L})$ were stirred 
continuously and kept at $18{ }^{\circ} \mathrm{C}$ in constant light $\left(185 \mu \mathrm{mol} \mathrm{m}{ }^{-2} \mathrm{~s}^{-1}\right)$. Subsamples from the surplus culture collected in an overflow container were taken daily to measure the cell density of the cultures with a CASY cell counter (Schärfe System CASY Cell Counter and Analyser System) and to ensure the cultures remained in steady state. To harvest algae from the chemostats for feeding the copepods sampling containers were placed under the overflow to collect algae for the duration of $1 \mathrm{~h}$ each day. Subsamples from these containers were used for the determination of the algal densities and the volume corresponding to the 50,000 cells per copepod per day was pipetted into the containers with the copepods for feeding.

\section{Copepods}

Copepod eggs were obtained from a culture of the calanoid copepod A. tonsa kept in filtered natural seawater (salinity 32) in a $200 \mathrm{~L}$ tank at $18{ }^{\circ} \mathrm{C}$ under a 18:6 light:dark (L:D) regime. The copepods were fed a mixture of the algae $R$. salina and the heterotrophic flagellate Oxyrrhis sp. Eggs were siphoned off the bottom of the tank daily and stored in an airtight container in seawater at $4{ }^{\circ} \mathrm{C}$ until use. No eggs older than 3 months were used in the experiments.

The copepod eggs were incubated in artificial seawater (salt: hw Marinemix, www.hw-wiegandt.de; in deionised water) adjusted to a salinity of 32 . The copepods were hatched in $5 \mathrm{~L}$ containers; the nauplii hatched in the first $24 \mathrm{~h}$ were discarded. The nauplii hatched in the next $24 \mathrm{~h}$ were separated from the remaining unhatched eggs and were divided into $1 \mathrm{~L}$ glass containers at densities of 1,000 individuals $\mathrm{L}^{-1}$ in five replicates per treatment to ensure the animals were all of the same age at the beginning of the experiment. The nauplii were first fed $24 \mathrm{~h}$ later, when it could be assumed that they had reached the first feeding second naupliar stage (Landry 1983). The copepods were kept at $18{ }^{\circ} \mathrm{C}$ in dim light conditions under ambient $p \mathrm{CO}_{2}$ and fed 50,000 cells of $R$. salina per individual and day (corresponding to $\sim 3 \mathrm{mg} \mathrm{C} \mathrm{L}^{-1} \mathrm{day}^{-1}$ ), irrespective of the algal $p \mathrm{CO}_{2}$ treatment. This concentration is considered ad libitum for copepods.

All experimental animals were transferred to fresh artificial seawater daily prior to feeding in order to avoid changes in the nutrient composition of the algae by waste products of the animals. The artificial seawater was stored at $18{ }^{\circ} \mathrm{C}$ and constantly aerated.

The copepods in the growth experiment were fed on the algae cultured under one of the three different $p \mathrm{CO}_{2}$ conditions from the beginning and for a duration of 14 days. In order to strictly separate the food effects resulting from the increased carbon availability from direct effects caused by the increase in $\mathrm{CO}_{2}$ or change in $\mathrm{pH}$ on the grazers, the algae were cultured separately and fed to the consumers, which were kept under ambient $p \mathrm{CO}_{2}$ throughout. Water was changed daily prior to feeding, and the copepods were kept at $18{ }^{\circ} \mathrm{C}$ under dim light in a temperature controlled room.

The developmental stages of the copepods were determined for 100 individual animals from subsamples at the end of the experiment (stages 1-6 were assigned to the nauplii, 7-12 to the copepodites). All naupliar stages were pooled without discrimination, while copepodites were determined for their developmental stages. For the calculation of the developmental rates (stages $\mathrm{day}^{-1}$ ), all naupliar larvae were assigned to stage 6 , the last naupliar stage before transition to the copepodite stages. The number of individuals per stage was divided by the number of days of growth, and the developmental rate per treatment was then calculated by dividing this sum by the number of individuals counted, i.e., 100.

\section{Short-term exposure}

The effects of short-term exposure ( 3 days) to algae grown under different $p \mathrm{CO}_{2}$ were tested on juvenile and adult copepods which were previously fed algae grown under ambient $p \mathrm{CO}_{2}$ levels. The reaction of the copepods to the changes in their food $p \mathrm{CO}_{2}$ levels was tested by measuring the DOC excretion and respiration rates of the two different stages.

\section{Phytoplankton}

To ensure constant supply and food quality for the experiment, new batch cultures of $R$. salina were inoculated daily for every treatment with a starting concentration of $0.5 \times 10^{6}$ cells $\mathrm{L}^{-1}$. The algae were cultivated in $1 \mathrm{~L}$ batch cultures in $\mathrm{f} / 2$ growth medium at a constant temperature of $18{ }^{\circ} \mathrm{C}$ under high light $\left(185 \mu \mathrm{mol} \mathrm{m} \mathrm{m}^{-2} \mathrm{~s}^{-1}\right)$ and a $16: 8 \mathrm{~h}$ L:D regime. Algae were constantly aerated through a glass tube with a mixture of air and pure $\mathrm{CO}_{2}$ adjusted to one of three different experimental $p \mathrm{CO}_{2}$ levels and harvested after a growth period of 4 days. The algal cell densities of subsamples from the experimental algae were measured as described above. The required volumes of algae for feeding were taken directly from the culture bottles by pipette and added to the containers with the copepods.

Algae grown in $\mathrm{f} / 2$ medium under ambient $p \mathrm{CO}_{2}$ conditions were fed to the copepods for 10 or 16 days, respectively, after which the copepods were switched to one of the algae grown under the experimental $p \mathrm{CO}_{2}$ conditions $(200,400$ or $800 \mu \mathrm{atm})$. Samples for the analysis of $\mathrm{C}, \mathrm{N}$ and $\mathrm{P}$ were taken each day when the algae were fed to the copepods. For the statistical analysis, the data from each of the algal treatments were pooled. 


\section{Copepods}

In order to investigate the effect of short-term exposure to algae cultivated under different $p \mathrm{CO}_{2}$ conditions on copepods of different developmental stages, the animals were first reared on $R$. salina cultivated in $\mathrm{f} / 2$ medium under ambient $p \mathrm{CO}_{2}$ conditions for 10 or 16 days. The copepods for the second experiment were obtained from the same culture as the copepods in the first experiment. Copepod eggs were incubated in artificial seawater with a salinity of 32 as described for the growth experiment above. The animals were transferred to containers at densities of 1,000 individuals $\mathrm{L}^{-1} 24 \mathrm{~h}$ after hatching, assigned one of the three different algal $p \mathrm{CO}_{2}(200,400$ or $800 \mu \mathrm{atm}, 7$ replicates per treatment) treatments and fed these algae for a further 3 days until they had developed into copepodites or the adult stage, respectively. The copepods were kept at ambient $p \mathrm{CO}_{2}$ levels. Seven replicate copepod containers were incubated for each of the three algal $p \mathrm{CO}_{2}$ treatments for both developmental stages studied (copepodites and adults).

\section{Long-term exposure}

The effects of long-term exposure of copepods on algae grown under different $p \mathrm{CO}_{2}$ were assessed by measuring the respiration rate and DOC production of copepodites after 14 days. The same experimental set-up and organisms as described for the growth experiment above were used. Five replicates per treatment of copepods were fed algae grown under three different $p \mathrm{CO}_{2}$ in continuous chemostat cultures from the beginning.

\section{Analytical procedures}

Samples of the primary producers fed to the copepods were taken daily for the determination of nutrient stoichiometry. For the analysis of the primary producer $R$. salina approximately $4 \times 10^{6}$ cells were filtered onto pre-combusted and washed Whatman GF/F filters. The carbon and nitrogen content of the samples was measured with an Elementar vario MICRO cube CHN analyser (Elementar Analysensysteme, www.elementar.de).

Phosphorus was analysed as orthophosphate, after the method described by Grasshoff et al. (1999), following oxidative hydrolysis. The samples were treated with an oxidation agent $\left(\mathrm{K}_{2} \mathrm{~S}_{2} \mathrm{O}_{8}, \mathrm{H}_{3} \mathrm{BO}_{3}, \mathrm{NaOH}\right.$ in distilled water) under high pressure and at high temperature $\left(120^{\circ} \mathrm{C}\right)$ in an autoclave to convert the phosphorus compounds to the orthophosphate form. Molybdate-antimony-solution (containing ammonium molybdate $\left(\mathrm{NH}_{4}\right)_{6} \mathrm{Mo}_{7} \mathrm{O}_{24} \times 4 \mathrm{H}_{2} \mathrm{O}$, antimony potassium tartrate $\left.\mathrm{K}(\mathrm{SbO}) \mathrm{C}_{4} \mathrm{H}_{4} \mathrm{O}_{6} \times 0,5 \mathrm{H}_{2} \mathrm{O}\right)$ and ascorbic acid were added to the solute before the P-content was measured photometrically.
Copepod respiration rates were determined by means of a microsensor oxygen metre (PreSens Precision Sensing, Germany) equipped with oxygen microoptodes. Copepods were washed over a sieve $(75 \mu \mathrm{m}$ mesh size) to separate them from any primary producers before being introduced into the $5 \mathrm{~mL}$ incubation vessel. An average number of 75 copepodites and 50 adult copepods from each replicate (seven replicates per treatment for the short-term experiments and five replicates per treatment for the long-term experiment) were incubated for $1 \mathrm{~h}$ at the same constant temperature at which they were kept during the experiment $\left(18^{\circ} \mathrm{C}\right)$. Copepods were allowed to adapt to the new environment for $5 \mathrm{~min}$ before the measurement started. Oxygen air saturation values were below $80 \%$ at the end of all measurements. Bacterial respiration rates were measured as a control treatment at the same time and the measured bacterial respiration rates deduced from the total respiration rates of the copepod measurements. The animals were collected and counted after the incubation to determine the precise number of animals in each vessel, permitting an accurate calculation of respiration rates per individual animal. The temperature in the reparation vessels did not change during the measurements. Respiration rates were calculated by linear regression of oxygen concentration over time. The resulting oxygen consumption rate was converted to carbon production ( $\mu \mathrm{g} \mathrm{C}$ individ$\mathrm{ual}^{-1} \mathrm{~h}^{-1}$ ) by means of the Respiratory Quotient (RQ) (Ikeda et al. 2000). This RQ is the ratio of carbon dioxide produced to oxygen consumed. A value of 1 was assumed for the RQ for all animals, based on values for carbohydrate metabolism from Prosser (1961) and Gnaiger (1983) (reviewed by Ikeda et al. 2000).

For the determination of the DOC excreted by the copepods, the copepods were sieved $(75 \mu \mathrm{m}$ mesh size) in order to avoid primary producers entering the incubation vial. For each of the replicates, 200 copepodites or 75 adult copepods were gently washed into the incubation container with the help of a wash bottle filled with artificial seawater. This artificial seawater was mixed according to the specifications by Grasshoff et al. (1999). The incubation chamber was filled to a volume of $20 \mathrm{~mL}$ with the same artificial seawater and sealed with a piece of pre-combusted aluminium foil. The vial was returned to the temperature control room and kept at $18{ }^{\circ} \mathrm{C}$ in a dark box for $1 \mathrm{~h}$. After $1 \mathrm{~h}$, the water was filtered into a pre-treated brown glass vial over a pre-combusted and washed Whatman GF/F filter which retained the copepods. The filters were stained with Lugol's solution, and the copepods on the filter were counted. The sample was then acidified by the addition of $100 \mu \mathrm{l}$ of $\mathrm{HCl}(25 \%)$ before being sealed and stored in a dark fridge at $4{ }^{\circ} \mathrm{C}$ until analysis (Elementar Analysensysteme vario TOC cube; www.elementar.de). All of the glassware used in the preparation of the DOC sample were 
previously washed in $10 \% \mathrm{HCl}$ and rinsed with ultrapure water (Milli-Q Integral Water Purification System, Millipore).

\section{Statistical analyses}

The C:N and C:P ratios of the primary producer $R$. salina from both experimental set-ups were analysed as dependent variables with a one-factorial ANOVA, after testing for homogeneity of variances (StatSoft Statistica 7), using $\mathrm{CO}_{2}$ treatments as the factor. For the analysis of the respiration and the DOC excretion rates of the copepods, a one-factorial design was used with the carbon losses (respiration and DOC excretion) as the dependent variables and the $\mathrm{CO}_{2}$ treatments as the factorial explanatory variable. The developmental rates of the copepodites were analysed as the dependent variables in a one-way ANOVA with the $\mathrm{CO}_{2}$ treatments as factorial explanatory variable. Tukey's honest significant difference test was used as the post hoc test in all cases.

\section{Results}

\section{Growth}

The stoichiometry of the algae grown in the continuous chemostat cultures was affected by the exposure to the different $p \mathrm{CO}_{2}$ during growth. Both the $\mathrm{C}: \mathrm{N}$ ratios $\left(F_{2,19}=44.46, P<0.0001\right)$ and the C:P $\left(F_{2,18}=159.57\right.$, $P<0.0001)$ ratios differed significantly and increased with increasing $p \mathrm{CO}_{2}$ content of the air (Fig. 1).

The development of the copepods was significantly affected by the different $p \mathrm{CO}_{2}$ treatments of their food source (Fig. 2). Consequently, the developmental rates of the copepods reared on $R$. salina from the different $p \mathrm{CO}_{2}$ treatments were significantly different $\left(F_{2,10}=60.67\right.$, $P<0.001$ ), with the lowest rate of development observed in the copepods fed the $R$. salina from the $800 \mu$ atm treatment, those with the highest carbon-to-nutrient ratios (Fig. 3).

\section{Short-term exposure}

The stoichiometry of the algae showed significant differences as a result of the different $p \mathrm{CO}_{2}$ levels they were exposed to. Not surprisingly, the carbon-to-nutrient ratios were higher in the high $\mathrm{CO}_{2}$ treatments. The $\mathrm{C}: \mathrm{N}$ and $\mathrm{C}: \mathrm{P}$ ratios of $R$. salina were significantly affected by $\mathrm{CO}_{2}$ concentration $\left(F_{2,26}=33.16, P<0.001\right.$ and $F_{2,12}=13.68$, $P<0.001$, respectively). Both ratios increased with $\mathrm{CO}_{2}$, although differences between individual treatment levels were not always significant (Fig. 4a, b).

The copepods were affected by the different amounts of carbon in their food. The juvenile copepodite stages emitted significantly higher amounts of carbon through respiration with increasing carbon content of the algae $\left(F_{2,13}=6.9, P<0.01\right)$ (Fig. 5a). The amount of carbon excreted in the form of DOC (Fig. 5b, note differing scales) also showed significant differences between treatments $\left(F_{2,10}=10.17, P<0.01\right)$. The pattern, however, was reversed. The highest amount of carbon as DOC was exuded by the copepodites fed on the algae from the lowest $\mathrm{CO}_{2}$ treatment $(200 \mu \mathrm{atm})$.

The adult copepods exposed to the algae grown under different $p \mathrm{CO}_{2}$ levels reacted differently compared to the juvenile copepodites. The respiration rate was significantly lower in the copepods fed on the algae from the intermediate $\mathrm{CO}_{2}$ treatment $(400 \mu \mathrm{atm})$ (Fig. 5c), which corresponds to present-day $p \mathrm{CO}_{2}$ levels, compared to the respiration rate for the two other treatments $\left(F_{2,9}=17.97\right.$, $P<0.001)$. The amount of carbon discharged as DOC by the adult copepods showed an inverse pattern to the respiration rate (Fig. 5d); the amount of carbon excreted in the copepods fed on the algae from the $400 \mu$ atm treatment was significantly higher compared to the two other treatments $\left(F_{2,11}=19.51, P<0.001\right)$.

Thus, the pathway by which the copepods exuded the carbon was different between the two ontogenetic stages investigated in this experiment (Fig. 6). The juvenile copepodites exuded significantly more carbon through respiration than DOC $\left(F_{1,23}=73.79, P<0.001\right)$.
Fig. 1 Stoichiometric measures (molar C:N ratio in panel a; molar C:P ratio in panel $\mathbf{b}$ ) of $R$. salina grown in continuous chemostat cultures under three different $p \mathrm{CO}_{2}$ treatments ( $N=13$ per treatment). Statistical differences $(P<0.05$ Tukey's honest significant difference (HSD) test) are indicated by letters. Error bars are standard deviation
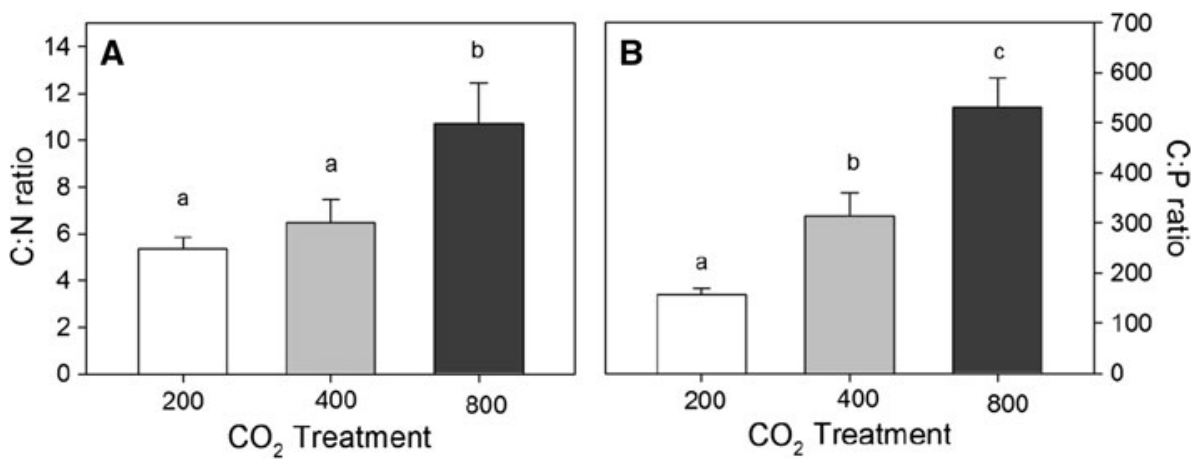


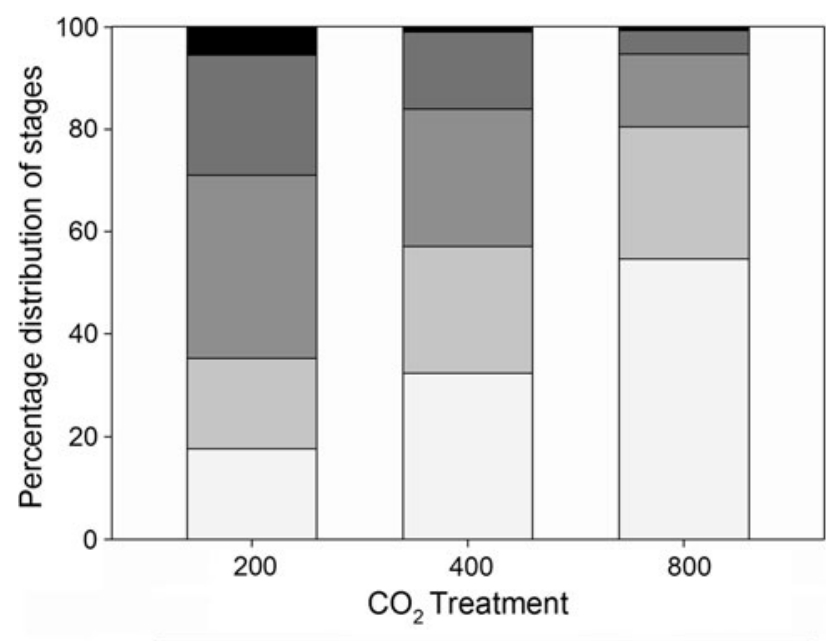

Nauplii $\square$ C1 $\square$ C2 $\square$ C3 $\square$ C4

Fig. 2 Growth rate experiment. Percentage distribution of the development stages of $A$. tonsa reared on the different $p \mathrm{CO}_{2} R$. salina

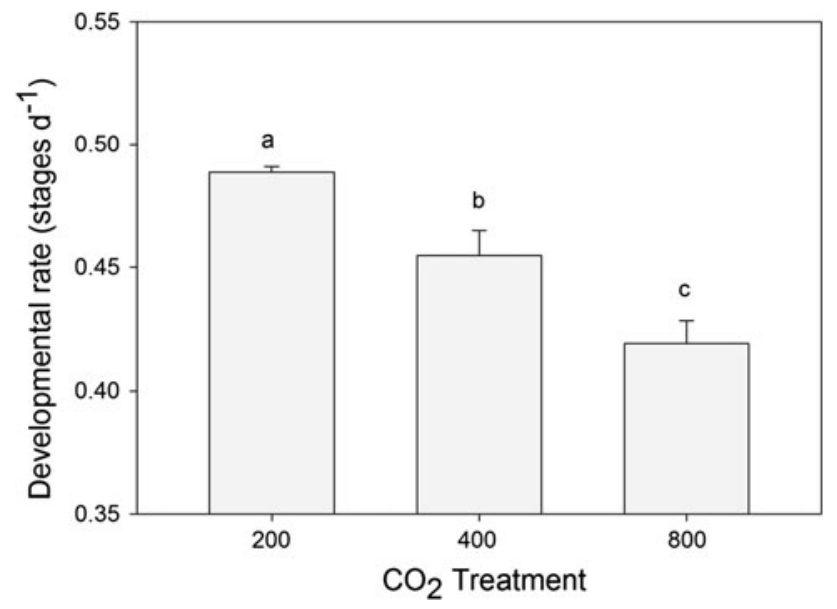

Fig. 3 Growth rate experiment. Developmental rates of A. tonsa reared on the different $p \mathrm{CO}_{2} R$. salina. Statistically significant differences $(P<0.05$ Tukey's honest significant difference (HSD) test) are indicated by letters
The adult copepods exposed to the differently cultivated algae on the other hand excreted a significantly higher amount of carbon as DOC than through respiration $\left(F_{1,20}=46.07, P<0.001\right)$.

The adult copepods excreted a significantly higher total amount of carbon than the copepodites $\left(F_{1,43}=95.62\right.$, $P<0.0001$ ), which is to be expected as they have a much higher biomass. However, even corrected for individual body weight, the differences in the amount of DOC exuded were significant, with the adult copepods still excreting higher amounts than the copepodites.

No significant differences in the final densities of the copepods were detected between treatments for the copepodites $\left(F_{2,16}=0.63, P=0.55\right)$ and the adult copepods $\left(F_{2,18}=1.55, P=0.24\right)$, indicating that the treatments had no effect on the mortality of the animals, but remained stable (around 5-10\% per day).

\section{Long-term exposure}

The juvenile copepods reared on the algae from the different $\mathrm{CO}_{2}$ treatments displayed an increased respiration rate with increasing $\mathrm{C}$ content of their food (Fig. 7a). The respiration rate was significantly higher in the copepods reared on the algae from the $800 \mu$ atm treatment $\left(F_{2,10}=4.04, P=0.05\right)$. The effect of the elevated carbon-to-nutrient ratio in the food was only marginally significant for the amount of carbon excreted as DOC (Fig. $7 b)$ by the copepodites $\left(F_{2,6}=3.98, P=0.079\right)$.

The copepodites reared on the differently cultivated algae excreted higher amounts of carbon through respiration than as DOC $\left(F_{1,16}=124.84, P<0.001\right)$ (Fig. 8). Nevertheless, the pattern was similar to the short-term exposure, displaying decreasing DOC production with increasing $p \mathrm{CO}_{2}$. The copepodites reared on the different algae in the long-term experiment showed a significantly higher rate of overall (from respiration and DOC release) carbon loss $\left(F_{1,39}=23.24, P<0.001\right)$ compared to the overall carbon loss for the copepodites from the second
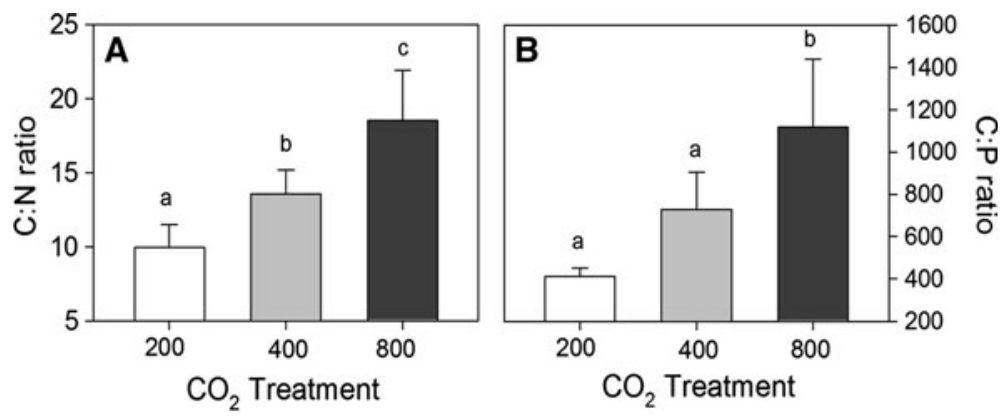

Fig. 4 Short-term experiment. Stoichiometric measures (molar C:N ratio in panel a; molar C:P ratio in panel $\mathbf{b}$ ) of $R$. salina grown under three different $p \mathrm{CO}_{2}$ treatments (data pooled from $N=7$ replicates).

Statistical differences $(P<0.05$ Tukey's honest significant difference (HSD) test) are indicated by letters. Error bars are standard deviation 
Fig. 5 Short-term experiment. Carbon loss rates

(mean + standard deviation for $N=7$ copepod samples per treatment) for copepodites $(\mathbf{a}, \mathbf{b})$ and adult copepods $(\mathbf{c}, \mathbf{d})$. Statistically significant differences $(P<0.05$ Tukey's honest significant difference (HSD) test) are indicated by different letters. Note different scales in DOC production between adults and copepodites
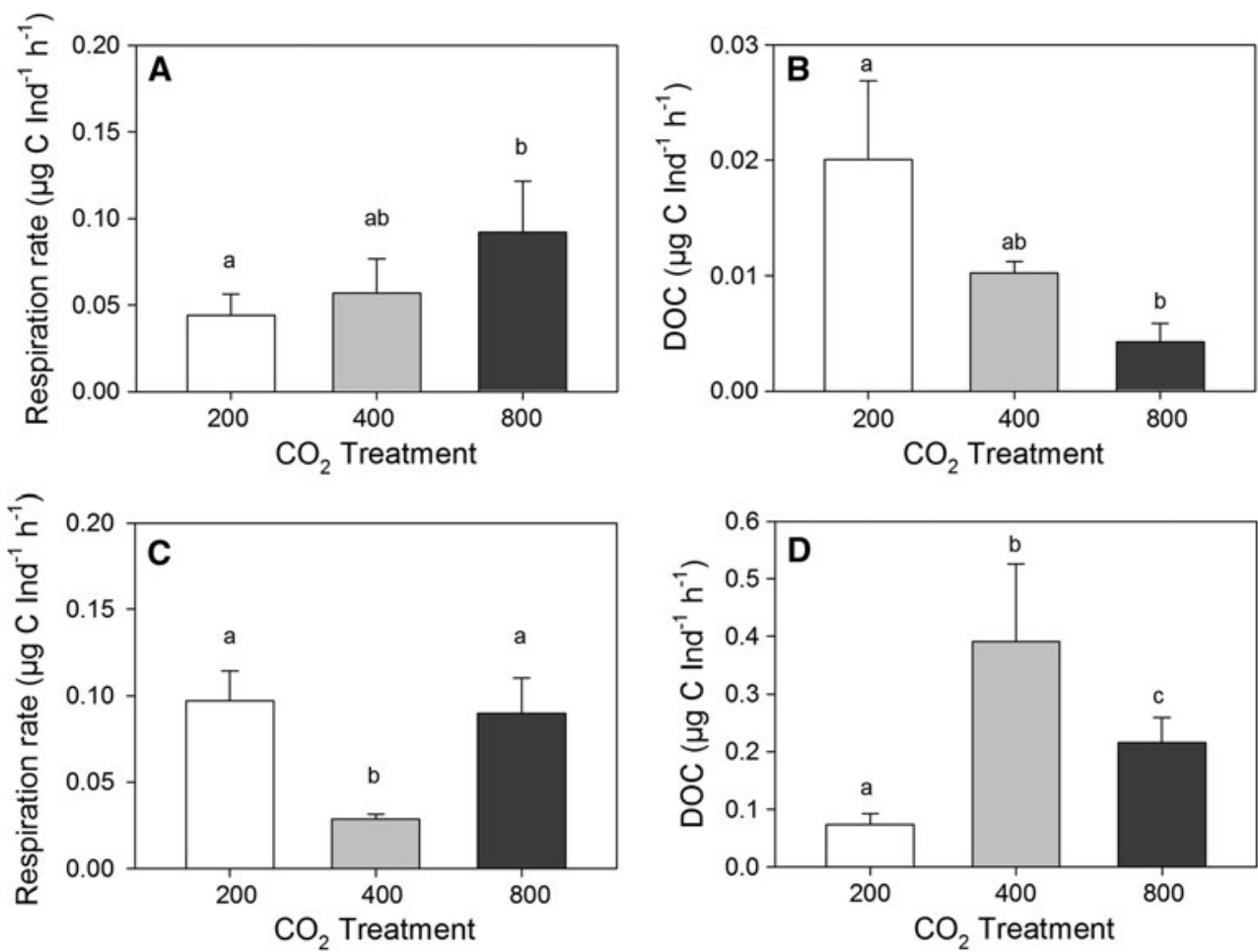

experiment, which were only exposed to the differently cultivated algae for a period of 3 days (comparing Figs. 6a, 8).

Even though the $\mathrm{C}: \mathrm{N}$ and $\mathrm{C}: \mathrm{P}$ ratios of the algae from the continuous chemostat cultures (Fig. 1) were lower than those from the algae grown in batch cultures (Fig. 4), the increased carbon availability led to severe nutrient limitations in both algae cultures.

As in the short-term experiment, the densities of the copepods at the end of the experiment were not significantly different $\left(F_{2,12}=0.06, P=0.93\right)$, and no effect of the treatments on the mortality was detected.

\section{Discussion}

This study showed that the primary producer used in this study increased their carbon content when cultured under elevated $p \mathrm{CO}_{2}$. The nutrient stoichiometry of the algae was altered by the reduction of the nutrient content relative to carbon.

Similar results to the ones in our study with regard to changes in nutrient stoichiometry have been reported from terrestrial plants and previous experimental studies with aquatic primary producers (Urabe et al. 2003; Riebesell et al. 2000, 2007; Burkhardt et al. 1999). To our knowledge, only two previous studies exist on the potential food chain effects of increased $\mathrm{CO}_{2}$ availability in a stoichiometric context (Urabe et al. 2003; Urabe and Waki 2009).
Urabe et al. (2003) observed increasing C:P ratios in the algae following higher $\mathrm{C}$ fixation under elevated $p \mathrm{CO}_{2}$. The authors reported higher algal but lower consumer growth rates under high $p \mathrm{CO}_{2}$, but did not measure other responses in the consumers regarding the reaction to the high carbon content of their food. Furthermore, as they dealt with a high phosphorus freshwater herbivore (Daphnia), it was not clear whether such effects would also be visible in a marine food chain. It can clearly be stated that this is the case.

Not only the nutrient stoichiometry of primary producers changes under different carbon-to-nutrient ratios but also other characteristics of the algae may change, such as digestibility (Van Donk et al. 1997) or toxicity (Nejstgaard et al. 1995). Furthermore, the biochemical composition may change, and the fatty acid content of algae is also susceptible to changes in carbon availability. We chose the cryptophyte $R$. salina, as this alga actually shows an increase in the concentrations of highly unsaturated (essential) fatty acids when grown under high carbon-tonutrient ratios, which potentially enhances its quality as a food source in terms of its biochemical composition (Malzahn et al. 2007, 2010). Therefore, all of the observed negative effects in the copepods here could be attributed to the direct changes in $\mathrm{C}$ content, rather than secondary biochemical changes in food quality. In contrast, the diatom Thalassiosira pseudonana contains less highly unsaturated fatty acids when grown under high $p \mathrm{CO}_{2}$ conditions (Rossoll et al. 2012). The authors also observed a decline in 
Fig. 6 Short-term experiment. Total carbon loss (mean values for each treatment, $N=7$ ) by copepodites (a) and adult copepods (b) fed on different $p \mathrm{CO}_{2} R$. salina. Statistically significant differences $(P<0.05$ Tukey's honest significant difference (HSD) test) are indicated by letters
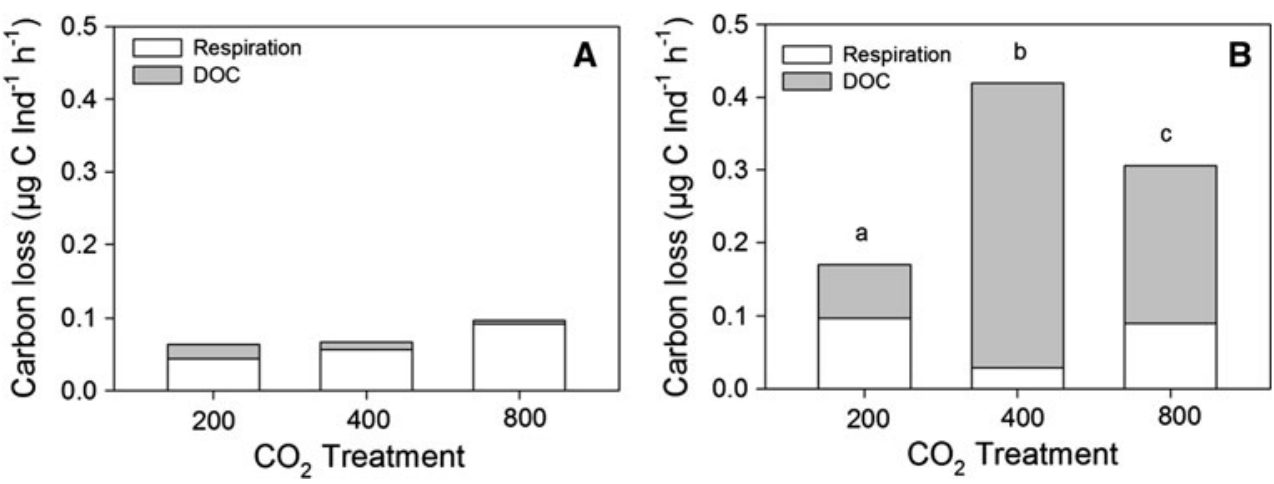

Fig. 7 Long-term experiment. Carbon loss rates

(mean + standard deviation for $N=5$ per treatment) for copepodites reared on different $p \mathrm{CO}_{2}$ algae. a respiration rates. b DOC. Statistically significant differences $(P<0.05$ Tukey's honest significant difference (HSD) test) are indicated by different letters
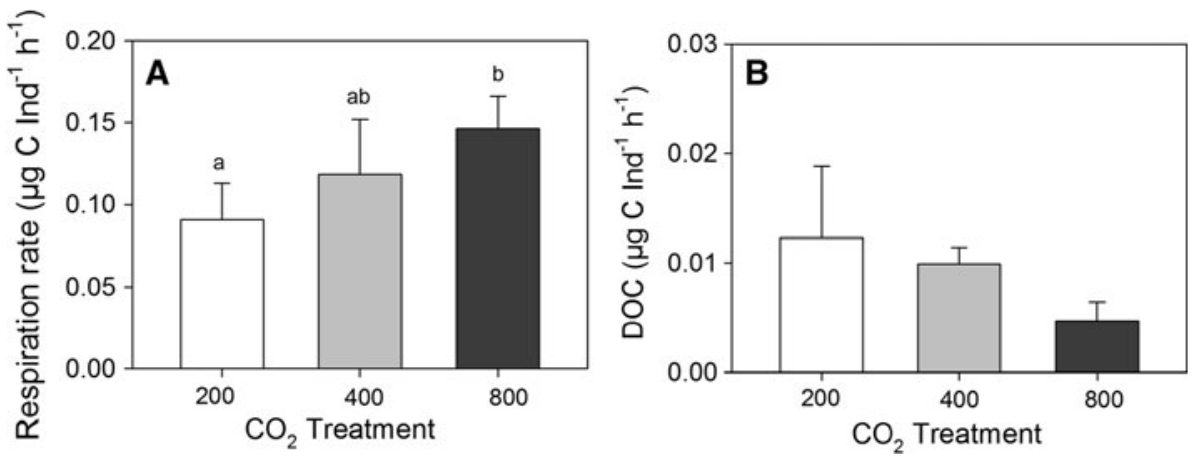

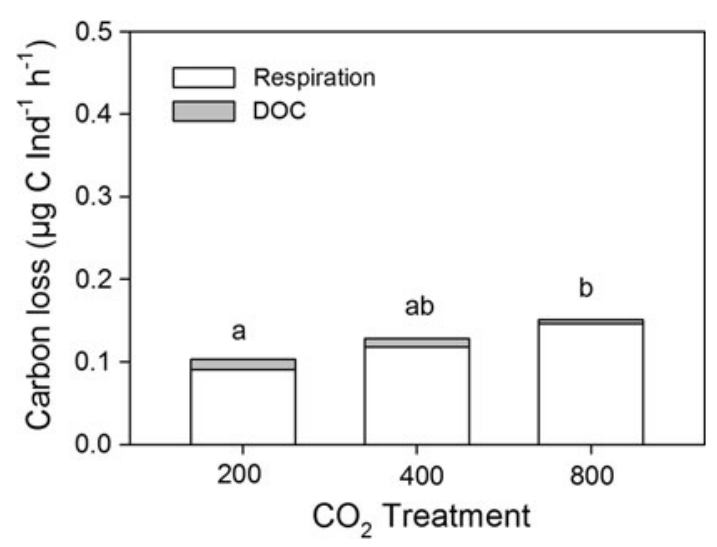

Fig. 8 Long-term experiment. Total carbon loss (mean values for $N=5$ in each treatment) by copepodites from the long-term experiment reared on different $p \mathrm{CO}_{2} R$. salina. Statistically significant differences $(P<0.05$ Tukey's honest significant difference (HSD) test) are indicated by letters

animal condition (in their case measured as egg production) with increasing $\mathrm{CO}_{2}$ availability in the food. They attributed these effects to the fatty acids, but since they did not report nutrient ratios in the algae it is not possible to discriminate between the two. Thus, several pathways and mechanisms may lead to the same result: declining animal performance with increasing $\mathrm{CO}_{2}$ availability of the food.

As grazers aim to maintain homoeostasis, the constraints imposed by food quality make it necessary for the consumers to dispose of surplus $\mathrm{C}$. This $\mathrm{C}$ cannot be efficiently used by the grazers, as the carbon-to-nutrient ratio does not meet their requirements for growth or reproduction. Furthermore, A. tonsa do not store large amounts of lipids. Thus, the routes and mechanisms by which this disposal of excess $\mathrm{C}$ is achieved and the nature and fate of these $\mathrm{C}$ excretory products may vary between species, and, as we have seen, even between life stagers within species (Darchambeau et al. 2003; Jensen and Hessen 2007; Plath and Boersma 2001; Sterner et al. 1998; Anderson et al. 2005; Hessen and Anderson 2008). The manner in which the consumers exude the $\mathrm{C}$ potentially affects both the consumers themselves and their environment. The preabsorption mechanisms available to consumers to regulate their carbon content favour the egestion of $\mathrm{C}$ in faecal pellets and the sequestration of this faecal matter (Anderson et al. 2005). Excess $\mathrm{C}$ voided in this manner is an important driver of the biological pump. The main pathways for the clearance of excess $\mathrm{C}$ considered in this study were the post-absorption mechanisms resulting in an increase of respiration rate to dispose of the $\mathrm{C}$ as $\mathrm{CO}_{2}$ and the exudation of $\mathrm{C}$ as DOC. Both of these pathways have been proposed as stoichiometric regulation mechanisms in herbivorous consumers fed on algae with high carbon-tonutrient ratios (e.g. Darchambeau et al. 2003; Jensen and Hessen 2007; Malzahn et al. 2010; Saba et al. 2009). Disposing of surplus $\mathrm{C}$ by respiration is a common mechanism, reported from a range of aquatic consumers including Daphnia, the copepod A. tonsa and the flagellate Oxyrrhis marina (Hantzsche and Boersma 2010; Malzahn 
et al. 2010; Jensen and Hessen 2007). Among the mechanisms proposed for the increase in respiration rate are increased activity, such as increased appendage beat rate (Jeyasingh and Weider 2007; Plath and Boersma 2001), so-called 'wastage' respiration (Zanotto et al. 1997) and respiration decoupled from other metabolism in the form of increased heat production (Trier and Mattson 2003). The increased metabolic activity underlying these mechanisms for the disposal of leftover $\mathrm{C}$ appears to come at a cost to the consumer (Hessen and Anderson 2008; Raubenheimer and Simpson 1999), although the exact nature of these costs is still not entirely clear (see Hessen and Anderson 2008). The copepodites investigated in this present study showed increasing respiration rates with an increase of carbon in their food. Higher body-specific respiration rates in juvenile stages suggest that juvenile copepods use respiration to dispose of excess $\mathrm{C}$ as $\mathrm{CO}_{2}$ and regulate their homoeostasis (He and Wang 2008; Laspoumaderes et al. 2010; Darchambeau et al. 2003), a pattern which has been reported from other juvenile zooplankton species (Jensen and Hessen 2007; Malzahn et al. 2010). Because larval and juvenile stages need high amounts of $\mathrm{P}$ to build the P-rich RNA necessary for high somatic growth (Sterner and Elser 2002; Malzahn and Boersma 2012), they are more likely to be P-limited and face an excess of carbon than the fully grown adult stages. Larval stages also have a high demand for $\mathrm{N}$, which is needed as a building block for proteins to support rapid growth (Sterner and Elser 2002). The copepodites therefore released high amounts of $\mathrm{C}$ by increasing their respiration rate. An increase in $\mathrm{CO}_{2}$ through increased consumer respiration rates may further enhance algal growth (Riebesell et al. 2007). This feedback scenario would create an even C-richer environment, which would further less efficient energy transfer mechanisms to higher trophic levels.

The adult copepods in this experiment showed a different pathway for eliminating $\mathrm{C}$ and exuded more DOC than $\mathrm{CO}_{2}$. A possible reason for this may be the fact that adult copepods have different nutrient requirements than the juvenile stages. Following the transition from somatic growth during juvenile stages to maintenance metabolism and reproductive growth, adult copepods are more likely to become $\mathrm{N}$-limited than P-limited, and furthermore, as they prepare for $\mathrm{C}$-intense reproduction, they are more likely to face C-limitation than nutrient limitations (Mauchline 1998). As the exudation of DOC has been suggested to be less costly in terms of energy expenditure (Hessen and Anderson 2008), adult copepods aiming to adjust their stoichiometry without incurring high energy costs may dispose of excess $\mathrm{C}$ directly as DOC.

Carbon released by the consumers as DOC is readily available for heterotrophic organisms (Møller and Nielsen 2001). As such it could play a role in providing a substratum for the growth of heterotrophic bacteria (Vargas et al. 2007) and thus fuelling the microbial loop and likely impacting the structure and functioning of the microbial community (Møller and Nielsen 2001; Saba et al. 2009). The effects of elevated $p \mathrm{CO}_{2}$ on bacteria have so far only been studied under the aspect of direct ocean acidification via changes in the $\mathrm{pH}$, which seems to have little effect (Allgaier et al. 2008). A stimulation of bacterial growth could in turn intensify competition for nutrients between phytoplankton species, resulting in nutrient limitation and potentially leading to a shift in phytoplankton community composition.

Most experimental studies on non-calcifying phytoplankton organisms have not described any strong impacts of direct ocean acidification on photosynthetic rates of primary producers (Beardall et al. 2009; Hein and SandJensen 1997; Giordano et al. 2005), but rather an increase in biomass of the primary producers (Riebesell et al. 2007; Urabe et al. 2003; Hein and Sand-Jensen 1997; Tortell et al. 1997). The observed effects on marine phytoplankton were mainly due to an increase in the availability of carbon and subsequent changes in the carbon-to-nutrient stoichiometry of the algal cells (Urabe and Waki 2009; Hessen and Anderson 2008). Direct $\mathrm{pH}$ effects seem to be of lesser importance in non-calcifying organisms at higher trophic levels as well (Mayor et al. 2007). Several studies have investigated the direct effects of ocean acidification on copepods, although effects varied between species copepods were affected by high $p \mathrm{CO}_{2}$, especially after longer exposure (Watanabe et al. 2006). While elevated $p \mathrm{CO}_{2}$ did not seem to affect the adult copepods tested (Kurihara and Ishimatsu 2008; Kurihara et al. 2004; Mayor et al. 2007), hatching rates were negatively affected by high $p \mathrm{CO}_{2}$ and low pH (Kurihara et al. 2004; Mayor et al. 2007). A negative effect on reproduction, however, was reported only for conditions above 5,000 $\mu$ atm (Kurihara and Ishimatsu 2008). The mortality of larval stages was also found to increase with increasing $p \mathrm{CO}_{2}$ and decreasing $\mathrm{pH}$ in some cases (Kurihara et al. 2004). It therefore appears that the younger stages of copepods are the most vulnerable, both to the direct (acidification) and the indirect (food quality) effects of increased $p \mathrm{CO}_{2}$.

The combination of the direct impact of elevated $p \mathrm{CO}_{2}$ on the copepods in combination with the indirect effect on their food needs to be investigated. The increase of the carbon-to-nutrient ratios of the primary producers under high $p \mathrm{CO}_{2}$ conditions reduces the food quality at the base of the food web and may negatively affect production of herbivorous consumers as well as their growth. Reduced growth may potentially have detrimental consequences for higher trophic levels by reducing the trophic transfer rate of energy and matter. Lower growth rates of copepods, as observed in this study, may lead to lower availability of 
food for the next trophic level and thus potentially affect the recruitment of higher trophic levels. A mismatch in food quality at the bottom of the food chain may therefore lead to a food quantity shortage at the higher trophic levels and negatively affect food chain production (Sterner et al. 1998). Furthermore, quality effects have also been shown to travel up the food chains, and the effects of this reduced food quality will affect higher trophic levels as well, potentially further impacting the functioning of the whole ecosystem by reducing the trophic transfer efficiency (Schoo et al. 2012).

Moreover, the differences in the carbon exudation pathways between the juvenile and adult stages could impact the marine ecosystem in the future high carbon oceans by altering interactions and community composition both at the bottom of the food web in the microbial loop and at the primary producer-herbivore interface as well as by affecting productivity of the lower trophic levels in the food web. It remains to be seen whether our finding with the one strain of Acartia tonsa can be translated to the outside world. If so, understanding the different excretory pathways even in discrete age classes of the same species will be of utmost importance to our overall understanding of trophic interactions in our acidifying world.

Acknowledgments We would like to thank the German Federal Ministry of Education and Research (BMBF) for funding. This study was part of the BIOACID Project and we are grateful for the support and feedback from our colleagues, particularly Stefanie Schnell. Special thanks are due to Bettina Oppermann and Julia Haafke for technical support. We thank Sam Dupont and two Reviewers, whose comments greatly improved the manuscript.

\section{References}

Allgaier M, Riebesell U, Vogt M, Thyrhaug R, Grossart HP (2008) Coupling of heterotrophic bacteria to phytoplankton bloom development at different $\mathrm{pCO}_{2}$ levels: a mesocosm study. Biogeosci Discuss 5:317-359

Anderson TR, Hessen DO, Elser JJ, Urabe J (2005) Metabolic stoichiometry and the fate of excess carbon and nutrients in consumers. Am Nat 165(1):1-15

Beardall J, Stoijkovic S, Larsen S (2009) Living in a high $\mathrm{CO}_{2}$ world: impacts of global climate change on marine phytoplankton. Plant Ecol Divers 2(2):191-205

Boersma M (2000) The nutritional quality of P-limited algae for Daphnia. Limnol Oceanogr 45(5):1157-1161

Boersma M, Aberle N, Hantzsche FM, Schoo KL, Wiltshire KH, Malzahn AM (2008) Nutritional limitation travels up the food chain. Int Rev Hydrobiol 93(4-5):479-488

Boersma M, Becker C, Malzahn AM, Vernooij S (2009) Food chain effects of nutrient limitation in primary producers. Mar Freshw Res 60(10):983-989

Burkhardt S, Zondervan I, Riebesell U (1999) Effect of $\mathrm{CO}_{2}$ concentration on $\mathrm{C}: \mathrm{N}: \mathrm{P}$ ratio in marine phytoplankton: a species comparison. Limnol Oceanogr 44(3):683-690

Darchambeau F, Færøvig PJ, Hessen DO (2003) How Daphnia copes with excess carbon in its food. Oecologia 136(3):336-346
DeMott WR, Tessier AJ (2002) Stoichiometric constraints vs. algal defenses: testing mechanisms of zooplankton food limitation. Ecology 83(12):3426-3433

Gervais F, Riebesell U (2001) Effect of phosphorus limitation on elemental composition and stable carbon isotope fractionation in a marine diatom growing under different $\mathrm{CO}_{2}$ concentrations. Limnol Oceanogr 46(3):497-504

Giordano M, Beardall J, Raven JA (2005) $\mathrm{CO}_{2}$ concentrating mechanisms in algae: mechanisms, environmental modulation, and evolution. Ann Rev Plant Biol 56:99-131

Gnaiger E (1983) Calculation of energetic and biochemical equivalents of respiratory oxygen consumption. In: Gnaiger E, Forstner $\mathrm{H}$ (eds) Polarographic oxygen sensors. Springer, Berlin, pp 337-345

Grasshoff K, Kremling K, Ehrhardt M (1999) Methods of seawater analysis. Wiley-VCH, Germany

Guillard RR, Ryther J (1962) Studies of marine planktonic diatoms. Can J Microbiol 8:229-239

Hantzsche FM, Boersma M (2010) Dietary-induced responses in the phagotrophic flagellate Oxyrrhis marina. Mar Biol 157:16411651

He X, Wang W-X (2008) Stoichiometric regulation of carbon and phosphorus in P-deficient Daphnia magna. Limnol Oceanogr 53(1):244-254

Hein M, Sand-Jensen K (1997) $\mathrm{CO}_{2}$ increases oceanic primary production. Nature 388:526

Hessen DO, Anderson TR (2008) Excess carbon in aquatic organisms and ecosystems: physiological, ecological, and evolutionary implications. Limnol Oceanogr 53(4):1685-1696

Ikeda T, Torres JJ, Hernández-León S, Geiger SP (2000) Metabolism. In: Harris R (ed) ICES zooplankton methodology manual. Academic Press, San Diego, pp 455-532

Jensen TC, Hessen DO (2007) Does excess dietary carbon affect respiration of Daphnia? Oecologia 152:191-200

Jeyasingh PD, Weider LJ (2007) Fundamental links between genes and elements: evolutionary implications of ecological stoichiometry. Mol Ecol 16:4649-4661

Kuffner IB, Andersson AJ, Jokiel PL, Rodgers KS, Mackenzie FT (2007) Decreased abundance of crustose coralline algae due to ocean acidification. Nat Geosci 1:114-117

Kurihara H, Ishimatsu A (2008) Effects of high $\mathrm{CO}_{2}$ seawater on the copepod (Acartia tsuensis) through all life stages and subsequent generations. Mar Pollut Bull 56:1086-1090

Kurihara H, Shimode S, Shirayama Y (2004) Effects of raised $\mathrm{CO}_{2}$ concentrations on the egg production rate and early development of two marine copepods (Acartia steuri and Acartia erythraea). Mar Pollut Bull 49:721-727

Landry MR (1983) The development of marine calanoid copepods with comment on the Isochronal Rule. Limnol Oceanogr 28(4): 614-624

Laspoumaderes C, Modenutti B, Balseiro E (2010) Herbivory versus omnivory: linking homeostasis and elemental imbalance in copepod development. J Plankton Res 32(11):15731582

Malzahn AM, Boersma M (2012) Effects of poor food quality on copepod growth are dose dependent and non-reversible. Oikos 121(9):1408-1416

Malzahn AM, Aberle N, Clemmesen C, Boersma M (2007) Nutrient limitation of primary producers affects planktivorous fish condition. Limnol Oceanogr 52(5):2062-2071

Malzahn AM, Hantzsche FM, Schoo KL, Boersma M, Aberle N (2010) Differential effects of nutrient-limited primary production on primary, secondary or tertiary consumers. Oecologia 162(1): $35-48$

Mauchline J (1998) The biology of calanoid copepods, vol 33. Advances in marine biology. Academic Press, New York 
Mayor DJ, Matthews C, Cook K, Zuur AF, Hay S (2007) $\mathrm{CO}_{2^{-}}$ induced acidification affects hatching success in Calanus finmarchicus. Mar Ecol Prog Ser 350:91-97

Møller EF, Nielsen TG (2001) Production of bacterial substrate by marine copepods: effect of phytoplankton biomass and cell size. J Plankton Res 23(5):527-536

Nejstgaard JC, Båmstedt U, Bagøien E, Solberg PT (1995) Algal constraints on copepod grazing. Growth state, toxicity, cell size, and season as regulating factors. ICES J Mar Sci 52(3-4):347-357

Nielsen LT, Jakobsen HH, Hansen PJ (2010) High resilience of two coastal plankton communities to twenty-first century seawater acidification: evidence from microcosm studies. Marine Biol Res 6(6):542-555

Plath K, Boersma M (2001) Mineral limitation of zooplankton: stoichiometric constraints and optimal foraging. Ecology 82: 1260-1269

Prosser CL (1961) Oxygen: respiration and metabolism. In: Prosser CL, Brown FA Jr (eds) Comparative animal physiology. W.B. Saunders, Philadelphia, pp 165-211

Raubenheimer D, Simpson SJ (1999) Integrating nutrition: a geometrical approach. Entomol Exp Appl 91(1):67-82

Riebesell U, Revill AT, Holdsworth DG, Volkman JK (2000) The effects of varying $\mathrm{CO}_{2}$ concentration on lipid composition and carbon isotope fractionation in Emiliania huxleyi. Geochim Cosmochim Acta 64(24):4179-4192

Riebesell U, Schulz KG, Bellerby RGJ, Botros M, Fritsche P, Meyerhofer M, Neill C, Nondal G, Oschlies A, Wohlers J, Zöllner E (2007) Enhanced biological carbon consumption in a high $\mathrm{CO}_{2}$ ocean. Nature 450:545-548

Rossoll D, Bermúdez R, Hauss H, Schulz KG, Riebesell U, Sommer U, Winder M (2012) Ocean acidification-induced food quality deterioration constrains trophic transfer. PLoS ONE 7(4):e34737. doi:10.1371/journal.pone. 0034737

Rost B, Riebesell U, Burkhardt S, Sultemeyer D (2003) Carbon acquisition of bloom-forming marine phytoplankton. Limnol Oceanogr 48(1):55-67

Saba GK, Steinberg DK, Bronk DA (2009) Effects of diet on release of dissolved organic and inorganic nutrients by the copepod Acartia tonsa. Mar Ecol Prog Ser 386:147-161

Saba GK, Steinberg DK, Bronk DA (2011) The relative importance of sloppy feeding, excretion, and fecal pellet leaching in the release of dissolved carbon and nitrogen by Acartia tonsa copepods. J Exp Mar Biol Ecol 404:47-56

Schoo KL, Aberle N, Malzahn AM, Boersma M (2010) Does the nutrient stoichiometry of primary producers affect the secondary consumer Pleurobrachia pileus? Aquat Ecol 44(1):233-242

Schoo KL, Aberle N, Malzahn AM, Boersma M (2012) Food quality affects secondary consumers even at low quantities: an experimental test with larval European lobster. PLoS ONE 7(3): e33550. doi:10.1371/journal.pone. 0033550
Sterner RW, Elser JJ (2002) Ecological stoichiometry: the biology of elements from molecules to the biosphere. Princeton University Press, Princeton, NJ

Sterner RW, Clasen J, Lampert W, Weisse T (1998) Carbon: phosphorus stoichiometry and food chain production. Ecol Lett 1(3): $146-150$

Swanson AK, Fox CH (2007) Altered kelp (Laminariales) phlorotannins and growth under elevated carbon dioxide and ultraviolet-B treatments can influence associated intertidal food webs. Glob Change Biol 13(8):1696-1709

Tortell PD, Reinfelder JR, Morel FMM (1997) Active uptake of bicarbonate by diatoms. Nature 390(6657):243-244

Tortell PD, DiTullio GR, Sigman DM, Morel FMM (2002) $\mathrm{CO}_{2}$ effects on taxonomic composition and nutrient utilization in an Equatorial Pacific phytoplankton assemblage. Mar Ecol Prog Ser 236:37-43

Trier TM, Mattson WJ (2003) Diet-induced thermogenesis in insects: a developing concept in nutritional ecology. Environ Entomol 32(1):1-8

Urabe J, Waki N (2009) Mitigation of adverse effects of rising $\mathrm{CO}_{2}$ on a planktonic herbivore by mixed algal diets. Glob Change Biol 15:523-531

Urabe J, Togari J, Elser JJ (2003) Stoichiometric impacts of increased carbon dioxide on a planktonic herbivore. Glob Change Biol 9(6):818-825

van de Waal DB, Verschoor AM, Verspagen JMH, van Donk E, Huisman J (2010) Climate-driven changes in the ecological stoichiometry of aquatic ecosystems. Front Ecol Environ 8(3): $145-152$

Van Donk E, Lürling M, Hessen DO, Lokhorst GM (1997) Altered cell wall morphology in nutrient-deficient phytoplankton and its impact on grazers. Limnol Oceanogr 42(2):357-364

Vargas CA, Cuevas LA, González HE, Daneri G (2007) Bacterial growth response to copepod grazing in aquatic ecosystems. J Mar Biol Assoc UK 87:667-674

Watanabe Y, Yamaguchi A, Ishida H, Harimoto T, Suzuki S, Sekido Y, Ikeda T, Shirayama Y, Takahashi MM, Oshumi T, Ishizaka J (2006) Lethality of increasing $\mathrm{CO}_{2}$ levels on deep-sea copepods in the Western North Pacific. J Oceanogr 62:185-196

Wiltshire KH, Malzahn AM, Kai Wirtz K, Greve W, Janisch S, Mangelsdorf P, Manly BFJ, Boersma M (2008) Resilience of North Sea phytoplankton spring blooms dynamics: an analysis of long term data at Helgoland Roads. Limnol Oceanogr 53(4): 1294-1302

Zanotto FP, Gouveia SM, Simpson SJ, Raubenheimer D, Calder PC (1997) Nutritional homeostasis in locusts: is there a mechanism for increased energy expenditure during carbohydrate overfeeding? J Exp Biol 200(18):2437-2448 